\title{
EFFECT OF THE USE OF VIDEOS IN THE PRE-CLASS PREPARATION OF LABORATORY SESSIONS TAUGHT BY FLIP TEACHING
}

\author{
José M. Meseguer-Dueñas ${ }^{1}$, Susana Quiles ${ }^{1}$, Roser Sabater i Serra ${ }^{2}$, María- \\ Antonia Serrano ${ }^{1}$, José A. Gómez-Tejedor ${ }^{1}$, Tania García-Sánchez ${ }^{2}$, Isabel Tort- \\ Ausina ${ }^{1}$, José Molina-Mateo', M. A. Gámiz-González', Jaime Riera ${ }^{1}$, Ana \\ Vidaurre ${ }^{1}$ \\ ${ }^{1}$ Departamento de Física Aplicada, Universitat Politècnica de València (SPAIN) \\ ${ }^{2}$ Departamento de Ingeniería Eléctrica, Universitat Politècnica de València (SPAIN)
}

\begin{abstract}
Nowadays, it is well stablished the effectiveness of flip teaching in different areas. Video is widely used as a pre-class learning material and it is progressively replacing text-document materials. The students, 70 in total, are enrolled in the laboratory practice of the subject of Physics (Bachelor's Degree: Industrial Electronics and Automation Engineering) at the Universitat Politècnica de València. Student's perception data were collected from the results of a survey. Students were asked about the usefulness of the videos and the in-class work, paying special attention to the roll of the instructor in relation to the flip teaching methodology and the pre-class material. The students were divided into two groups. In one of them, the videos were recorded by the same instructor present at the lab session, whereas the other group, the videos used were recorded by instructors different from the instructor present at the lab. The results indicate that students feel that the videos are very useful, rather than the written documents. They attribute a high value to the instructor in the lab session as they feel more confident with their work and they can ask for help when needed. They value positively the possibility of work autonomously. Small differences have been found in the opinion of both groups being the higher in the question that concerns the preference of the videos respect to the text.
\end{abstract}

Keywords: Flip teaching, videos as pre-class material, roll of the teacher.

\section{INTRODUCTION}

The aim of education is to provide students with knowledge and learning opportunities that enhance their skills and abilities such as ability to solve problems, learning to think and also communication skills. In the last years, different new pedagogical methodologies that incorporate the use of new technologies has been developed in order to achieve successfully this goal [1]-[3]. One of the innovative teaching models, the flipped classroom, are gaining popularity in recent years [4].

Flip teaching is a hybrid approach to learning, using technology to change the classical classroom lecture to homework and use the classroom time for interactive learning [5]. The effectiveness of flip teaching is well stablished in different areas. Several studies indicate that the learning gain is higher in STEM disciplines (Science, Technology, Engineering and Mathematics) than in non-STEM, as stated in the review of Huber and Werner [6]. Flip teaching can be defined as a pedagogical approach in which typical activities where students first receive instruction in the classroom and, after that, do their homework outside the classroom are reversed in order, challenging the conventional order of teaching and learning [7]. This methodology involves students in learning, allowing them to learn at their own and therefore they have more flexibility to distribute their studying time, but also putting on them more responsibility in the learning process [8], [9]. It allows students flexibility in their learning because they can access to the study material inside and outside the classroom environment as many times as they need. In pursuing this, a large number of digital, electronic and mobile technological tools (multimedia technology among them) are available to instructors, enabling them to improve the learning experience.

One of the multimedia tools that can be included in the inverted classroom are screencasts. A screencast is a video tutorial that combines the image with the verbal explanation of an instructor. Digital video is a pedagogical tool with positive cognitive results because it improves students' understanding. Many studies have focused on analysing the effectiveness of the pedagogical results in the learning of students who provide video as learning tools [10]. It has been reported its efficacy in 
teaching subjects based on skills, such as physics or mathematics, not only in theoretical concepts, but also in laboratory sessions [11]-[14]. In addition to the pedagogical advantages, screencasts videos give the students the possibility to see them whenever and wherever they want, visualising the explanation as many times as they need to understand the contents and therefore, facilitating their learning.

Using this tool in laboratory sessions, students previously prepare the session at home (objectives, background knowledge and experimental procedure) making use of the video prepared by instructors and thus, the entire lab session can be dedicated to the experimental work and student-centred active learning. It changes the instructor role, so that his/her function is to observe, supervise, criticise, guide and discuss the students work instead of just transmit detailed instructions. Video is used as a preclass learning material, progressively replacing text-document materials.

In the present work, carried out to the students of physics of the first year of the Bachelor Degree on Electronic Engineering at the Universitat Politècnica de València (UPV), we compare the use of videos with text-documents that students use at home to prepare the lab sessions and analyse the influence of the presence of the instructor during its development. In addition, we also analyse whether the evaluation of the videos depends on the presence during the lab session of the same instructor who has prepared the videos. This study is based on opinion surveys and instructors' observation with the aim to get further in the following questions: do students prefer videos to text documents as pre-class material? Does it have any influence on the students' opinion that the class instructor and the video instructor be the same?

\section{METHODOLOGY}

Before the lab sessions the necessary learning material was made available to students through the Universitat Politècnica de València online teaching platform called PoliformaT [15] based on Sakay [16]. The learning materials consisted of videos and written documents explaining the purpose and the procedure of the experience. It was given the explanation of the work that students must do in the lab session, and instructions for the equipment they had to handle. In the lab, the students worked in groups of three under teacher supervision. 24 students being the lecturer the same who had prepared all the audio-visual material (screencast) formed one group (Group 1). 46 students formed the other group (Group 2) and two lecturers were simultaneously involved in the laboratory; the videos used were recorded by instructors different from the instructors present at the lab.

At the end of the course, an anonymous survey was conducted to obtain student's perception about the use of videos in the laboratory and the role of the teacher in the lab sessions (see Table 1). The survey consisted of 18 questions and an open-ended question in which the students could give their opinion on the general content. The survey was completed by $50 \%$ of the students, and $15 \%$ of them answered the open-ended question. The 18 quantitative questions, on a Five-point Likert scale [17] were converted into a numerical scale from 0 to 10 in the following way: strongly agree (10), agree (7.5), neutral (5), do not agree (2.5), and strongly disagree (0). From the numerical scale, average results were calculated.

Table 1. Students' survey.

1 Before attending lab sessions, I prefer to watch the videos rather than read the written material

2 The videos helped me better understand the content of the lab practices.

3 The videos were helpful because I could see when I wanted.

4 The videos were easy to understand.

5 The procedures of the practices were sufficiently explained in the videos.

6 The videos were useful to perform laboratory practices.

7 Performing the lab practice has helped me to better understand the concepts contained in the videos.

8 With the videos, at the beginning of the laboratory practice I already have the necessary knowledge to do it without help.

9 In addition to reading the written document and watching the video at home, I think a little explanation from the teacher is needed before starting lab practice.

10 The presence of the teacher gives me security that the job is well done. 
11 With the written material and the videos, without the presence of the teacher, I would also be able to do the lab.

12 The teacher's criticism, discussion, and guidance help us get the most out of the lab.

13 I prefer that the procedures and timing of performing the laboratory practice be set by the teacher.

14 I find it appropriate that the teacher in the lab to be the same person who creates the videos.

15 It is better to use the same video format in all laboratory practices.

16 I like the fact that the teacher allows us to do the laboratory work autonomously and supervises our work.

17 I would prefer that the teacher will explain the procedures and objectives of the lab at the beginning of the class.

18 I would like to have a written guide to the laboratory practice that will tell me, step by step, what to do at each moment.

\section{RESULTS}

\subsection{Videos assessment}

Regards the assessment of the use of videos as pre-class material for the laboratory sessions, both groups coincide on the usefulness of this material for the preparation of the class. The average between 7 and 8 in questions Q2 and Q6 confirm this fact (Fig. 1). They find an advantage in being able to consult them wherever and whenever they want (Q3). These responses reinforce the use of screencast as pre-class material in FT in the laboratory. In the open-ended question, a student summarizes it clearly: "Very useful videos, in comparison to the texts, make the preparation of the lab session somewhat more dynamic and less monotonous, especially more visual and facilitates my understanding."

Comparing the video with the text material (Q1), both groups prefer the videos, although the difference is higher in the Group 1 in which its instructor has recorded the videos. Both groups agree, with similar differences between them, in that the videos are easy to understand (Q4) and that the practice is sufficiently explained (Q5). The students also agree that it is better to use the same video format for all practices (Q15). In addition, Group 1 consider more appropriate (almost one point above the other) that the teacher who prepare the videos be the same as the one in the laboratory (Q14).
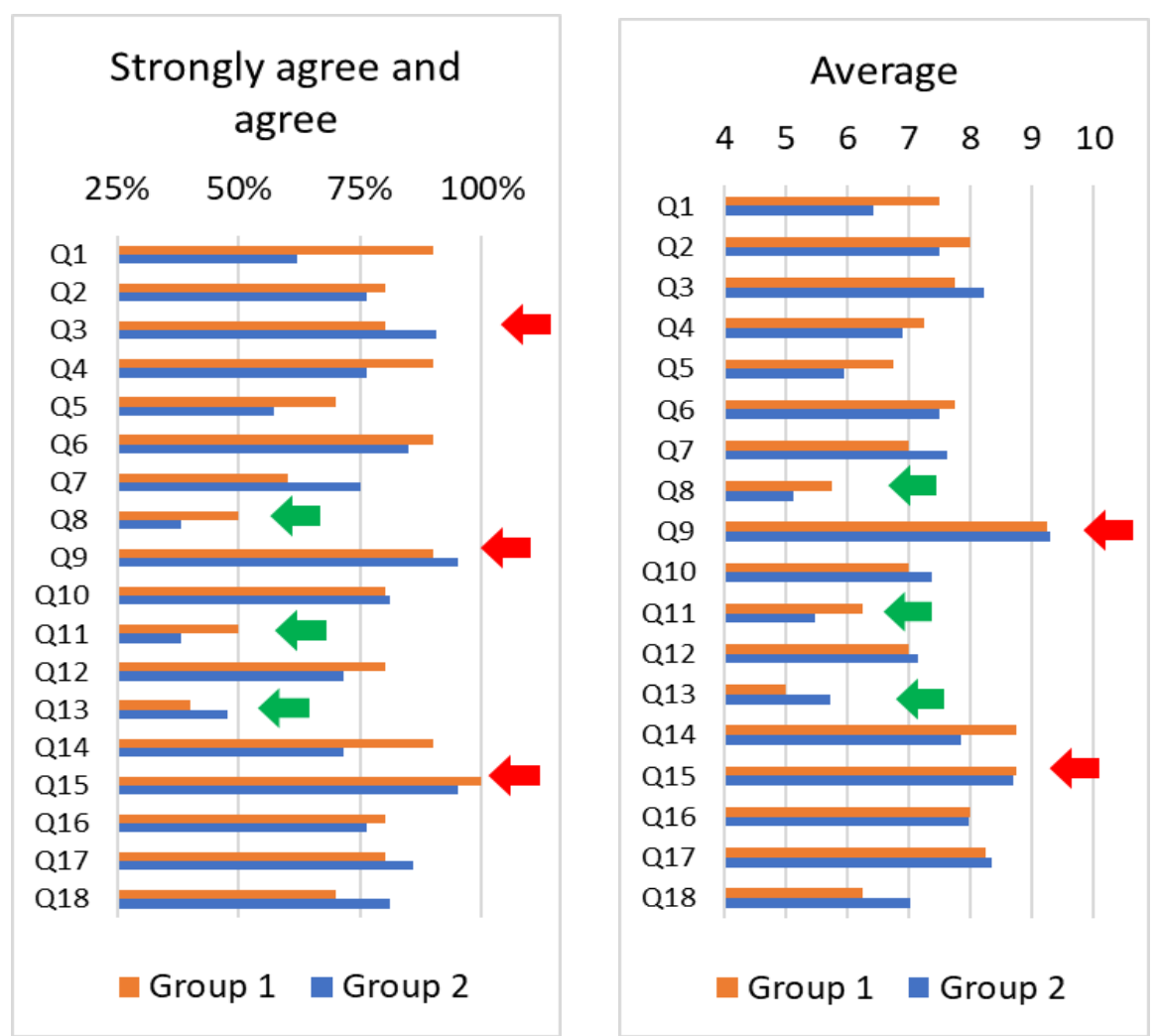

Figure 1. For each group and by question: a) Strongly agree and agree (\%) and b) Average. 


\subsection{The role of the teacher}

Both groups consider relevant the presence of the teacher in the laboratory as can be seen in Table 2 . They appreciate a small explanation at the beginning of the class (more than $80 \%$ strongly agree and average of 9.3 in each group). When answering the open question some students state that, at the beginning of the session, "the concepts explained and the procedure to be followed should be reviewed". The teacher gives them security in their work (average 7 and 7.4 in Q10) and they consider teacher comments valuable (average 7 and 7.1 in Q12).

In the open-ended question we find comments that positively value the methodological change initiated by the teachers: "I'm glad there are professors who are interested in their students learning through complementary material, not just teaching a master class and that's it."

Table 2. Average, standard deviation and percentage of strongly agree and agree of the answers to the questions of the survey for each group.

\begin{tabular}{c|c|c|c|c|c|c}
\hline \multirow{2}{*}{ Questions } & \multicolumn{3}{|c|}{ Group 1 } & \multicolumn{3}{c}{ Group 2 } \\
\cline { 2 - 6 } & Average & $\begin{array}{c}\text { Standard } \\
\text { deviation }\end{array}$ & $\begin{array}{c}\text { Stronly } \\
\text { agree and } \\
\text { agree }\end{array}$ & Average & $\begin{array}{c}\text { Standard } \\
\text { deviation }\end{array}$ & $\begin{array}{c}\text { Stronly } \\
\text { agree and } \\
\text { agree }\end{array}$ \\
\hline 1 & 7.5 & 1.9 & $90 \%$ & 6.4 & 2.9 & $62 \%$ \\
\hline 2 & 8.0 & 1.9 & $80 \%$ & 7.5 & 2.4 & $76 \%$ \\
\hline 3 & 7.8 & 2.4 & $80 \%$ & 8.2 & 1.9 & $90 \%$ \\
\hline 4 & 7.3 & 1.8 & $90 \%$ & 6.9 & 1.9 & $76 \%$ \\
\hline 5 & 6.8 & 2.0 & $70 \%$ & 6.0 & 2.6 & $57 \%$ \\
\hline 6 & 7.8 & 2.8 & $90 \%$ & 7.5 & 2.7 & $85 \%$ \\
\hline 7 & 7.0 & 1.9 & $60 \%$ & 7.6 & 1.8 & $75 \%$ \\
\hline 8 & 5.8 & 2.0 & $50 \%$ & 5.1 & 2.7 & $38 \%$ \\
\hline 9 & 9.3 & 1.6 & $90 \%$ & 9.3 & 1.4 & $95 \%$ \\
\hline 10 & 7.0 & 1.9 & $80 \%$ & 7.4 & 2.5 & $81 \%$ \\
\hline 11 & 6.3 & 2.6 & $50 \%$ & 5.5 & 2.8 & $38 \%$ \\
\hline 12 & 7.0 & 1.9 & $80 \%$ & 7.1 & 2.2 & $71 \%$ \\
\hline 13 & 5.0 & 3.5 & $40 \%$ & 5.7 & 3.1 & $48 \%$ \\
\hline 14 & 8.8 & 1.7 & $90 \%$ & 7.9 & 2.1 & $71 \%$ \\
\hline 15 & 8.8 & 1.3 & $100 \%$ & 8.7 & 1.5 & $95 \%$ \\
\hline 16 & 8.0 & 1.9 & $80 \%$ & 8.0 & 2.6 & $76 \%$ \\
\hline 17 & 8.3 & 2.0 & $80 \%$ & 8.3 & 1.8 & $86 \%$ \\
\hline 18 & 6.3 & 2.8 & $70 \%$ & 7.0 & 2.3 & $81 \%$ \\
\hline
\end{tabular}

\subsection{Lab session}

The students value positively that they are given autonomy in the laboratory (average 8 in Q16). There is no consensus on the need for the teacher to set the pace and direct their work (average 5 and high standard deviation in the answers of Q13). The average is slightly higher (5.7) in Group 2, as can be seen in table 2, so that they are more favourable to the direct guidance of the professor. In the openended question, one student writes, "we have not had any problem with any practice". This opinion coincides with that of the teachers; they have not detected any problems in the realization of practices other than those presented with the traditional methodology.

Despite all this, and as one would expect, students show certain insecurity as can be seen in the results of questions Q8, Q11, Q17 and Q18. Results on Q8 and Q11 indicate that they are not confident on be able to perform the lab work without any help. And this can be correlated with the role they attribute to the teacher and has been commented yin the previous section. Nor is it surprising that students prefer an explanation of objectives and procedures at the beginning of the session (Q17) and a document detailing, step by step, what to do in the lab (Q18). 


\section{CONCLUSIONS}

As a general conclusion, students confirm the usefulness of the screencast as pre-class material in a FT methodology for the laboratory sessions of a physics subject. They prefer the videos rather than the written material. One of the aspects of the videos that our students highly appreciate is that they allow them to prepare the lab session at home with timing flexibility. Anyway, they would like to continue using the traditional material (detailed written guide).

They attribute a high value to the role of the teacher in the lab session: they appreciate the explanation at the beginning of the session, they feel more confident in their presence and ask them for guide. And, at the same time, they highly value the possibility of working autonomously. Which is not contradictory with the fact that some students feel the need of the teacher in the laboratory setting the pace of the session

From the result of the survey can be conclude that students prefer certain degree of homogeneity: the same format for all the videos, the same teacher in the lab that in the videos.

\section{ACKNOWLEDGEMENTS}

This work has been supported by the Universitat Politècnica de València through the Project of Innovation and Educational Improvement Program (Projects PIME/2018/B26 and PIME/2018/B25 Convocatoria de Proyectos de Innovación y Convergencia).

\section{REFERENCES}

[1] M. K. Watfa and D. Audi, "Innovative virtual and collaborative teaching methodologies," Behav. Inf. Technol., vol. 36, no. 7, pp. 663-673, 2017.

[2] E. T. Welsh, C. R. Wanberg, K. G. Brown, and M. J. Simmering, "E-learning: emerging uses, empirical results and future directions," Int. J. Train. Dev., vol. 7, no. 4, pp. 245-258, 2003.

[3] P. E. Sanderson, "E-Learning: strategies for delivering knowledge in the digital age," Internet High. Educ., vol. 5, no. 2, pp. 185-188, 2002.

[4] J. Bergmann and A. Sams, Flip your classroom: reach every student in every class every day. International Society for Technology in Education, 2012.

[5] K. Missildine, R. Fountain, L. Summers, and K. Gosselin, "Flipping the classroom to improve student performance and satisfaction," J. Nurs. Educ., vol. 52, no. 10, pp. 597-599, 2013.

[6] E. Huber and A. Werner, "A review of the literature on flipping the STEM classroom: Preliminary findings," in ASCILITE 2016 - Conference Proceedings - 33rd International Conference of Innovation, Practice and Research in the Use of Educational Technologies in Tertiary Education: Show Me the Learning, 2016, pp. 267-274.

[7] D. R. Garrison and N. D. Vaughan, Blended learning in higher education: framework, principles, and guidelines. Jossey-Bass, 2008.

[8] J. O'Flaherty and C. Phillips, "The use of flipped classrooms in higher education: a scoping review. Internet High Educ 25:85-95.," Internet High Educ 2585, vol. 25, pp. 85-95, 2015.

[9] D. González-Gómez, J. S. Jeong, D. Airado Rodríguez, and F. Cañada-Cañada, "Performance and Perception in the Flipped Learning Model: An Initial Approach to Evaluate the Effectiveness of a New Teaching Methodology in a General Science Classroom," J. Sci. Educ. Technol., vol. 25, no. 3, pp. 450-459, 2016.

[10] D. Zhang, "Interactive Multimedia-Based E-Learning: A Study of," Am. J. Distance Educ., vol. 19, no. 3, pp. 149-162, 2005.

[11] A. Vidaurre Garayo et al., "Use of Teaching Videos for Problem Solving Methodology," ICERI2017 Proc., vol. 1, no. November, pp. 4715-4722, 2017.

[12] J. Molina-Mateo, J. A. Gómez-Tejedor, A. Vidaurre, J. Riera, J. M. Meseguer-Dueñas, and I. TortAusina, "Screencast videos as a tool to enhance the teaching of physics," in Edulearn 16, 2016, pp. 8117-8127. 
[13] I. Tort-Ausina et al., "Analysis of the Use of Videos As Part of Flip Teaching in Laboratory Sessions in Engineering Degrees," ICERI2017 Proc., vol. 1, no. November, pp. 4783-4789, 2017.

[14] J. A. Gómez-Tejedor et al., "Effectiveness of flip teaching on engineering students' performance in the physics lab," Comput. Educ., vol. 144, no. September 2019, p. 103708, 2020.

[15] UPV, "PoliformaT. Universitat Politècnica de València," 2003. [Online]. Available: https://poliformat.upv.es/. [Accessed: 08-Jan-2020].

[16] Sakai, "Sakai Learning Management System," 2018. [Online]. Available: https://www.sakailms.org/. [Accessed: 08-Jan-2020]..

[17] R. Likert, "A technique for the measurement of attitudes.," Arch. Psychol., vol. 22, no. 140, pp. 1$55,1932$. 